\title{
Registro de Cyclocephala flavipennis Arrow, 1914 (Coleoptera: Melolonthidae) danificando plantas de mirtileiro no Brasil
}

\author{
Record of Cyclocephala flavipennis Arrow, 1914 (Coleoptera: Melolonthidae) injuring blueberry \\ plants in Brazil
}

\author{
Gabriela Inés Diez-Rodríguez $^{\mathbf{I}^{*}}$ Lucas Khun Hübner ${ }^{\mathrm{I}}$ Luis Eduardo Corrêa Antunes ${ }^{\mathrm{I}}$ \\ Jerson Vanderlei Carús Guedes ${ }^{\text {II }}$ Dori Edson Nava ${ }^{I}$ \\ - NOTA -
}

RESUMO

Larvas de Cyclocephala flavipennis Arrow, 1914, são comumente encontradas em cereais de inverno (trigo, cevada, aveia e triticale), milho e soja, no Rio Grande do Sul. Em março de 2012, larvas desta espécie foram detectadas em plantas de mirtileiro (Vaccinium ashei Reade), cultivar 'O'Neal', no municipio de Pelotas, RS. Os insetos alimentaram-se de raizes em áreas restritas do pomar. Este é o primeiro relato da ocorrência do coró-pequeno, C. flavipennis, em plantas de mirtileiro.

Palavras-chave: coró, danos, Vaccinium ashei.

\section{ABSTRACT}

Cyclocephala flavipennis Arrow, 1914 are usually found in winter cereals (wheat, barley, oat and triticale), corn and soybean in Rio Grande do Sul, Brazil. Larvae of the species were detected in blueberry (Vaccinium ashei Reade) cultivar 'O'Neal', in March 2012 in the city of Pelotas, RS, Brazil. The white grub fed up with roots in restricted areas from the orchard. This is the first record of $\boldsymbol{C}$. flavipennis in blueberry plants.

Key words: white grub, damage, Vaccinium ashei.

Apesar de sua recente introdução no Brasil, em 1983, o mirtileiro (Vaccinium ashei Reade) (Ericaceae) é amplamente cultivado no Hemisfério Norte, principalmente em países da Europa e nos Estados Unidos. Na América do Sul, Chile, Argentina e Uruguai são os maiores produtores, beneficiando-se da produção durante a entressafra europeia e norteamericana (FACHINELLO, 2008). Atualmente, a área cultivada com mirtileiro no Brasil é de cerca de 270 hectares, sendo as regiões Sul e Sudeste as maiores produtoras (ANUÁRIO BRASILEIRO DA FRUTICULTURA, 2013). Embora existam no mundo mais de 300 espécies de insetos que atacam o mirtileiro, apenas algumas apresentam importância econômica, constituindo problemas crônicos que requerem controle todos os anos (LARRAÍN et al., 2007).

Entre estas pragas, os córos constituem um grupo importante e diversificado, sendo problema em vários países. Denomina-se coró à fase larval das subfamílias Dynastinae, Melolonthinae, Rutelinae e Cetoniinae (Coleoptera: Scarabaeoidea: Melolonthidae) que vivem no solo e se alimentam de sementes e de raízes de plantas, além de outros substratos. No Brasil, menos de 1\% das 1.008 espécies de Melolonthidae estão associadas com danos nas culturas (MORÓN, 2004). As espécies rizófagas Diloboderus abderus Sturm, 1826, Phyllophaga triticophaga Morón \& Salvadori, 1998, Demodema brevitarsis (BLANCHARD, 1850) e Cyclocephala flavipennis Arrow, 1914, destacam-se entre as espécies de corós edafícolas encontradas em cereais de inverno, milho e soja, no sul do Brasil (PEREIRA \& SALVADORI, 2006; CHERMAN et al., 2013). $\boldsymbol{C}$. flavipennis, conhecido como coró-pequeno, apresenta uma geração por ano, sendo mais comum em lavouras com abundância de palha e em pastagens. As larvas, tipicamente escarabeiformes, com três pares de pernas e corpo de coloração branco-amarelada, não fazem galerias e possuem uma baixa capacidade

'Laboratório de Entomologia, Embrapa Clima Temperado, Rodovia BR 392, km 78, CP 403, 96010-971, Pelotas, RS, Brasil. E-mail: gidiez@gmail.com.*Autor para correspondência.

IIDepartamento de Proteção de Plantas, Centro de Ciências Rurais (CCR), Universidade Federal de Santa Maria (UFSM), Santa Maria, RS, Brasil. 
de causar danos, pois utilizam material vegetal em decomposição como alimento. Populações elevadas do inseto (80-100 larvas $\mathrm{m}^{-2}$ ) não ocasionam danos aos cereais de inverno (SALVADORI, 1999), razão pela qual não são considerados praga nessas culturas (PEREIRA \& SALVADORI, 2006). O trabalho teve por objetivo identificar e registrar a presença de larvas de melolontídeos encontradas em pomar de mirtileiro em Pelotas, RS.

A presença de larvas foi constatada no mês de março de 2012, em um talhão de aproximadamente 600 plantas de mirtileiro da cultivar ' $\mathrm{O}$ ' Neal' de 2 anos de idade, plantadas em espaçamento de $1 \mathrm{~m}$ na linha $\mathrm{x}$ $4 \mathrm{~m}$ nas entrelinhas. $\mathrm{O}$ pomar de 5 hectares se localiza no município de Pelotas, RS (31 ${ }^{\circ} 39$ ' 51" Latitude $\mathrm{S} ; 52^{\circ} 32^{\prime} 7^{\prime}$ " Longitude $\mathrm{W}$ e $135 \mathrm{~m}$ de altitude), em Argissolo Bruno-Acizentado Eutrófico e Argissolo Acizentado Eutrófico. Foram amostradas 20 plantas, sendo encontradas de 10 a 20 larvas da espécie causadora do dano, em cada uma. As larvas coletadas foram enviadas para o Laboratório de Manejo de Pragas - LabMIP - da Universidade Federal de Santa Maria, onde foi realizada a análise morfológica com auxílio de microscópio estereoscópico. Foi examinado o desenho de pêlos do raster das larvas, constatando-se serem $\boldsymbol{C}$. flavipennis (CHERMAN et al., 2013). Esta espécie, amplamente distribuída na região produtora de grãos da metade norte do Rio Grande do Sul (CHERMAN et al., 2014), pode também estar presente em outros locais do Estado, com impacto sobre culturas mais sensíveis aos danos radiculares. Nas plantas de mirtileiro infestadas, foi observada redução na quantidade de raízes secundárias (Figura 1), folhas amareladas e perda de vigor. Esses danos podem apresentar importância distinta aos causados em cereais de inverno, que, pela elevada densidade de plantas por área, convivem com o inseto. Já a densidade de plantas de mirtileiro é muito baixa e seu sistema radicular restrito, caracterizando a diferença entre as culturas e, possivelmente, a menor tolerância a esta espécie de corós.

Embora se trate do primeiro relato de ocorrência de $\boldsymbol{C}$. flavipennis em mirtileiro, outros coleópteros rizófagos têm sido encontrados danificando esta cultura em países vizinhos. No Chile, foram observados Hylamorpha elegans (BURMEISTER, 1844) (Coleoptera: Scarabaeidae) (LARRAÍN et al., 2007) e Aegorhinus superciliosus (GUÉRIN, 1830) (Coleoptera: Curculionidae) (PARRA et al., 2009). Na Argentina, observaram-

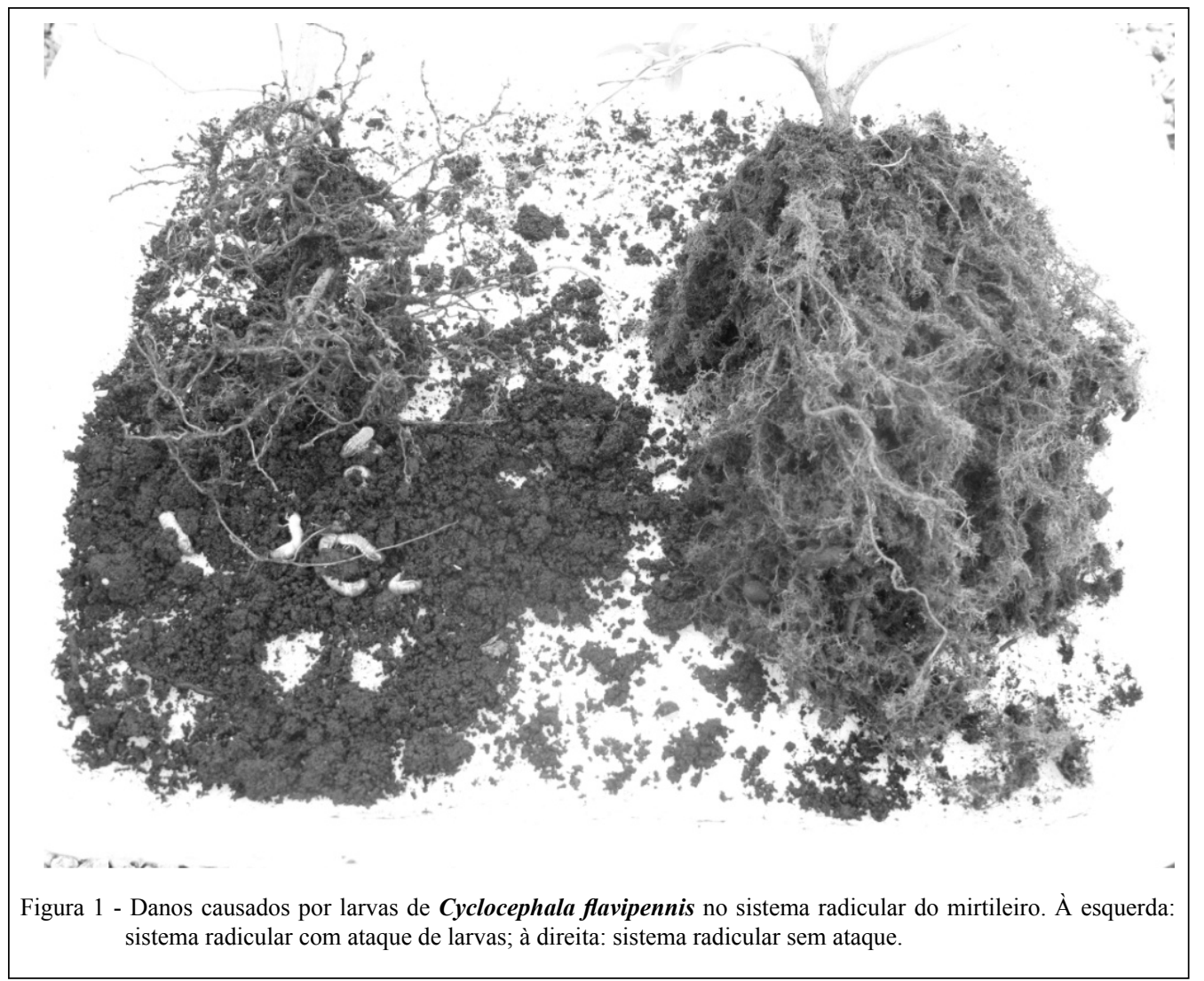

Ciência Rural, v.45, n.2, fev, 2015. 
se os curculionídeos: Naupactus xanthographus (GERMAR, 1824), N. cervinus (BOHEMAN, 1840) (DEL RÍO et al., 2010; ROCCA \& GRECO, 2011), Otiorhynchus ovatus (LINNAEUS, 1758) e Hyphantus sulcifrons BOHEMAN, 1843 (DEL RÍO et al., 2010). De acordo com MOLINA(2001), a adição de serragem e de acículas de pinho recomendada para promover a areação e proteção das raízes de mirtileiro, ao aumentar o conteúdo de matéria orgânica do solo, poderia influenciar na disponibilidade de habitat para larvas de Tropinota squalida (SCOPOLI, 1783) (Coleoptera: Scarabeidae), o que poderia ter acontecido para $\boldsymbol{C}$. flavipennis.

O trabalho relata a primeira ocorrência de C. flavipennis em mirtileiro no Brasil, oferecendo subsídios para futuros estudos relacionados ao seu manejo nesta frutífera, cuja área de cultivo vem crescendo nas regiões Sul e Sudeste do país.

\section{AGRADECIMENTOS}

À Coordenação de Aperfeiçoamento de Pessoal de Nível Superior (CAPES), pela bolsa concedida ao primeiro autor.

\section{REFERÊNCIAS}

ANUÁRIO BRASILEIRO DA FRUTICULTURA. Santa Cruz do Sul: Gazeta Santa Cruz, 2013. 136p. Disponível em: <http://www. grupogaz.com.br/editora/anuarios/show/3853.html >. Acesso em: 30 jan. 2014.

CHERMAN, M.A. et al. White grubs (Coleoptera, Melolonthidae) in the "Planalto Region", Rio Grande do Sul state, Brazil: key for identification, species richnessand distribution. Revista Brasileira de Entomologia, v.57, n.3, p.271-278, 2013. Disponível em: <http://www.scielo.br/scielo.php?pid=S0085$56262013000300005 \&$ script $=$ sci arttext $>$. Acesso em: 23 jan. 2014. doi: 10.1590/S0085-56262013000300005.

CHERMAN, M.A. et al. Ecological characterization of white grubs (Coleoptera: Melolonthidae) community in cultivated and noncultivated fields. Neotropical Entomology, v.43, n.3, p.282288, 2014. Disponível em: <http://download.springer.com/static/
pdf/550/art\%253A10.1007\%252Fs13744-014-0214-0.pdf?auth66 $=1402752637052 \mathrm{e} 567 \mathrm{f} 9 \mathrm{~d} 81 \mathrm{fa} 185 \mathrm{ed} 198 \mathrm{cf} 324 \mathrm{da} 2 \mathrm{~b} 9 \& \mathrm{ext}=. \mathrm{pdf}>$. Acesso em: 20 maio 2014. doi: 10.1007/s13744-014-0214-0.

DEL RÍO, M.G. et al. Gorgojos (Coleoptera: Curculionidae) perjudiciales para "frutos rojos" en la Argentina. Revista de la Sociedad Entomológica Argentina, v.69, n.1-2, p.101-110, 2010.

FACHINELLO, J.C. Mirtilo. Revista Brasileira de Fruticultura, v.30, n.2, n.p., 2008. Disponível em: <http://www.scielo.br/ scielo.php?pid=S0100-29452008000200001\&script $=$ sci arttext $>$. Acesso em: 25 jan. 2014. doi: 10.1590/S0100-29452008000200001.

LARRAÍN, P. et al. Plagas del arándano presentes en la región de Coquimbo. Intihuasi: INIA, 2007. 4p. (Informativo INIA n.29).

MOLINA, J.M. Incidencia de Tropinota squalida (Scopoli, 1783) (Coleoptera: Scarabaeidae) en el cultivo del arándano en Huelva (España). Problemática asociada a su control. Revista Aragonesa de Entomología, v.9, p.93-98, 2001.

MORÓN, M.A. Melolontídeos edafícolas. In: SALVADORI, J.R. et al. Pragas de solo no Brasil. Passo Fundo: Embrapa Trigo, Dourados: Embrapa Agropecuária Oeste, Cruz Alta: Fundacep Fecotrigo, 2004. Cap.4, p.133-166.

PARRA, L.B. et al. Estado del conocimiento sobre el cabrito del frambueso (CF), Aegorhinus superciliosus (Guérin) (Coleoptera: Curculionidae). Idesia, v.27, n.1, p.57-65, 2009.

PEREIRA, P.R.V.S.; SALVADORI, J.R. Guia para identificação de corós rizófagos (Coleoptera: Scarabaeoidea: Melolonthidae) comumente encontrados em cereais de inverno, milho e soja no norte do Rio Grande do Sul. Passo Fundo: Embrapa Trigo, 2006. 12p. (Embrapa Trigo. Comunicado Técnico Online, 204). Disponível em: <http://www.cnpt.embrapa.br/biblio/co/p_co204. htm>. Acesso em: 20 jan. 2014.

ROCCA, M.; GRECO, N. Diversity of herbivorous communities in blueberry crops of different regions of Argentina. Environmental Entomology, v.40, n.2, p.247-259, 2011. Disponível em: <http:// www.bioone.org.ez66.periodicos.capes.gov.br/doi/pdf/10.1603/ EN10206>. Acesso em: 15 jan. 2013. doi: 10.1603/EN10206.

SALVADORI, J.R. Manejo de corós em cereais de inverno. Passo Fundo: Embrapa Trigo, 1999. 3p. (Embrapa Trigo. Comunicado Técnico Online, 3). Disponível em: <http://www.cnpt.embrapa.br/ biblio/p_co03.htm>. Acesso em: 20 jan. 2014. 